\title{
'Visible-ness': the nature of communication for children admitted to a specialist children's hospital in the Republic of Ireland
}

\author{
Veronica Lambert, Michele Glacken and Mary McCarron
}

\begin{abstract}
Aim. This article presents the core concept of 'visible-ness' that emerged from an ethnographic study, which explored the nature of communication, for children (for ease of reading children refers to children and young people), admitted to a children's hospital in the Republic of Ireland.

Background. The importance of engaging with both child and family has been espoused as fundamental in promoting 'family'centred care. To date, studies have almost exclusively explored parents' and nurses' perspectives of the nature of parent participation and nurse-parent interactions and relationships. Although there is evidence of an emerging body of knowledge, which explores children's perspectives of their information, and communication needs, little is known empirically about the communication process between children and members of the health care team in inpatient hospital settings.
\end{abstract}

Design. The principles of ethnography underpinned the study design.

Method. Fieldwork took place over four months in one 35-bedded children's ward. Forty-nine children, ranging in ages from 6 to 16 years with a variety of medical and surgical conditions, participated. Various modes of data collection were employed, namely semi-participant observations, unstructured interviews, draw and write technique and a child-friendly 'stick a star' quiz. Results. The core concept to emerge was that of 'visible-ness'. 'Visible-ness' existed along a continuum consisting of two polar ends, 'being overshadowed' and 'being at the forefront'. These polar ends illuminated the degree to which children were, or wanted to be, included in the communication process and the extent to which children's agenda was addressed.

Conclusion. This study provides empirical insight into children's experiences of communication in an inpatient hospital setting. A key recommendation calls for the development of communication assessment strategies to determine the 'ideal' position children would like to occupy, at any given point in time, along the 'visible-ness' continuum.

Relevance to practice. This study emphasises the need for all health professionals to embrace the individualism of each child patient with regard to their specific communication needs.

Key words: children, communication, family, health professional, hospital, nurses, nursing

Accepted for publication: 11 April 2008

\section{Introduction}

Family-centred care (FCC) has long been promoted as the ideal model of care for delivering a quality service to hospitalised children. Smith et al. (2002, p. 20) offer a contemporary definition of what FCC encompasses; 'the professional support of the child and family through a process of involvement, participation and partnership underpinned by empowerment and negotiation'. This definition stresses the importance of involving both child and family in care delivered. One of the prerequisites for FCC is effective communication (Ahmann \& Johnson 2000). However, little
Authors: Veronica Lambert, PhD Candidate (School of Nursing \& Midwifery, Trinity College Dublin), RCN, RGN, BNS (Hons), Lecturer, School of Nursing, Dublin City University, Glasnevin, Dublin 9, Ireland; Michele Glacken, PhD, PG Dip (Adv Nurs), BSc (Hons), RGN, RM, Head of Department of Nursing \& Health Studies, St Angela's College, Sligo, Ireland; Mary McCarron, PhD,
Associate Professor of Nursing and Midwifery, School of Nursing \& Midwifery Studies, Trinity College Dublin, Dublin, Ireland Correspondence: Veronica Lambert, Lecturer, School of Nursing, Dublin City University, Glasnevin, Dublin 9, Ireland. Telephone: +35317007161.

E-mail: veronica.lambert@dcu.ie 
is known empirically about the communication process between children and members of the health care team in inpatient hospital settings.

To date, studies across a range of countries have almost exclusively explored parents' and nurses' perspectives of nurse-parent interactions/relationships (Brown \& Ritchie 1989, Espezel \& Canam 2003), parent participation/involvement in their child's care (Paliadelis et al. 2005, Lam et al. 2006, Ygge et al. 2006, Soderback \& Christensson 2007) and parental needs during their child's hospitalisation (Hallstrom et al. 2002, Shields et al. 2003, 2004). Alsop-Shields (2002) proposed a new philosophical model for paediatric nursing entitled the Parent-Staff Interaction Model of Pediatric Care. Within this model, the parent and child are regarded as a single unified entity. Arguably, within this concept of a single unified parent-child entity the child has become lost. This is not to devalue the role, position and voice of parents themselves in the care of their sick hospitalised child but rather to ensure 'the visibility of children, where they belong, at the centre of paediatric nursing practice' (Bricher 1999, p. 454). More research is needed to help us understand how best to communicate with children not only to achieve the goals of child and FCC but also to reach the vision of patientcentred care epitomised within many influential government publications (Department of Health \& Children 2000, Department of Health 2003).

The necessity for an evidence base on communication practices with children in health care is explicitly accentuated in several studies exploring children's views of hospital/health care (Horstman \& Bradding 2002, Carney et al. 2003, Boylan 2004, Salter \& Stallard 2004, Gibson et al. 2005, Kilkelly \& Donnelly 2006) and children's experiences of participation in health care consultations and decision making (Runeson 2002, Hallstrom \& Elander 2004, Coyne et al. 2006, Kelsey \& Abelson-Mitchell 2007). One dominant theme to emerge from these studies as a major concern for children of all ages was lack of communication. This is an area that requires further investigation owing to the significant dearth of research addressing health professional-child communication in hospital settings.

Some seminal (Strong 1979, Silverman 1987) and more recent work (Meeuwesen \& Kapten 1996, VanDulmen 1998, Tates et al. 2002) has focused on the health professionalparent-child triad as unit of analysis in an attempt to describe the nature of communication. However, these studies merely describe patterns of communication within single medical encounters at structured outpatient clinics. Furthermore, they neglect to explore the views of children themselves. Other studies have begun to specifically explore children's perspectives of their communication (Beresford \& Sloper 2003,
Young et al. 2003) and information needs (Ellis \& Leventhal 1993, Hooker 1997). The main focal point of these studies was the communication and information needs of chronically ill teenagers.

More recently, Smith and Callery (2005) explored children's (aged 7-11 years) information needs preroutine elective surgery. The findings of this study were of particular concern in that children reported knowing very little about hospital, their forthcoming admission and surgery. As Smith and Callery (2005) collected information from children prior to their admission to hospital, it is unknown whether these children received any information regarding their pending surgery while in hospital. With the exception of Shin and White-Traut's (2005) observational study, which involved young children aged five to six years in an inpatient unit in Korea, no studies were sourced which focused specifically on communication within paediatric in-patient hospital settings and for children admitted for wide-ranging medical and surgical care. Thus, the purpose of this ethnographic study was to explore the nature of communication for children admitted to a specialist children's hospital in the Republic of Ireland. This article presents the core theme to emerge from this study which was conceptualised as 'visibleness'.

\section{Method}

\section{Design}

There were four main reasons for choosing an ethnographic framework for this study. First, ethnography is an interpretivist approach being 'neither subjective nor objective' but rather 'mediating two worlds [audience and group studied] through a third [ethnographer]' (Agar 1986, p. 19). This allows for both etic (outside observer) and emic (inside participant) perspectives to be captured. Second, the context value of this approach meant that children's perspectives of communication would be captured within the everyday natural context of the children's ward. This creates a high degree of realism in which the researcher has limited control over events or behaviours (Hammersley \& Atkinson 1995). Third, the ability to flexibly integrate a combination of data collection tools facilitates a fluid, creative and developmental process of investigation (MacKenzie 1994, Johnson 1995). Fourth, spending an extensive period of time in the field helps to address such ethical and methodological considerations as the need to build rapport and trust with children and reduce the researcher's power status, whereby the researcher enters the world of the child as an active learner. The theoretical frameworks which guided the study were the 
Circular Transactional Model of Communication (Arnold 2003) and principles of Bronfenbrenner's (1979) Ecological Model of Human Development.

\section{Setting and sample}

Within ethnography, sampling is not only concerned with the selection of key informants, to give insight into the phenomena under study, but also with sampling across time and place (MacKenzie 1994). In this particular study the first author spent a total of 245 hours, as semi-participant observer, in one children's ward in a specialist children's hospital in the Republic of Ireland. The ward selected was chosen because it catered for a wide age range of children with both medical and surgical conditions. The ward consisted of 35 beds/cots segregated into six-ward areas which comprised of seven or eight beds, respectively. Child participants were purposively selected on the basis that they met the study's inclusion criteria: (1) they were admitted to the selected ward at the time of data collection; (2) they were admitted for an overnight stay; (3) they were aged between 6-16 years; (4) they were able and willing to take part and (5) they had parental consent. Children younger than six years and those too ill to participate were excluded. Forty-nine children participated in the study. The sample size was determined by the availability and accessibility of parents and children, in addition to admission rates and patient turnover. The background characteristics of the children are summarised in Table 1.

Table 1 Background characteristics of participants $(n=49)$

\begin{tabular}{lc}
\hline Characteristic & Number of participants \\
\hline Age & 29 \\
$6-11$ years & 20 \\
12-16 years & \\
Gender & 22 \\
Boys & 27 \\
Girls & \\
Mode of admission & 31 \\
Emergency & 13 \\
Elective & 4 \\
Out-patients & 1 \\
Inter-hospital transfer & \\
Diagnosis/reason for admission & 15 \\
Medical problem & 34 \\
Surgical problem & \\
Length of hospital stay & 40 \\
$\quad<7$ days & 5 \\
$\quad<14$ days & 4 \\
20-30 days & 30 \\
Previous hospitalisation & 19 \\
Yes & \\
No & \\
\hline
\end{tabular}

\section{Data collection}

Fieldwork was carried out over a four month period between 2004-2005. During this period prolonged time (a total of 245 hours), varying shifts and times, was spent daily on the children's ward to capture day-to-day experiences. Multiple modes of data collection were used (Fig. 1).

The sequence in which these methods were employed was not prescriptive and often occurred simultaneously. In her semi-participant observer role (Emond 2005), the first author was not part of the ward team and did not perform any hands on nursing duties. When she visited the children's ward daily, she interacted with the children playing games and watching television. Children often talked about things going on around them during such play activities. These close encounters with children provided a forum to observe health professionals attending to children and enabled the researcher to subsequently explore these observations with children. In line with Hammersley and Atkinson's (2007) contention, the dividing line between participant observation and informal interviewing was often hard to differentiate.

Interviews were in the form of informal conversations which took place spontaneously with the children on the open ward, whenever and wherever (bedside, corridor, play area) the opportunity arose. This avoided a rigid question answer framework and allowed free and natural discussion of children's unique perspectives (Hill et al. 1996, Ireland \& Holloway 1996). Furthermore, it enabled the first author to capture a holistic picture of what was going on, on the ward, and discuss 'here and now' experiences with children. Taking cognisance of children's maturity, individual interests and preferences, some of the younger children were also invited to draw scenes and write stories about when nurses and doctors came to talk to them (Pridmore \& Bendelow 1995, Bradding \& Horstman 1999) and/or complete a 'stick a star' quiz about communication during the informal interviews. This assisted with rapport building and the expression of younger children's views. The 'stick a star' quiz provided some structural guidance to help focus the conversation.

In the 'stick a star' quiz (Fig. 2), children were presented with a series of open-ended questions about communicating with health professionals. Examples of which are how much information does the nurse give you and how much does the nurse listen to you? To answer these questions, children allocated one (none/never), two (a little), three (some) or four stars (a lot) to health professionals. It was then further explored with children, why they allocated the number of stars they did and how health professionals could obtain 


\section{Semi-participant observation}

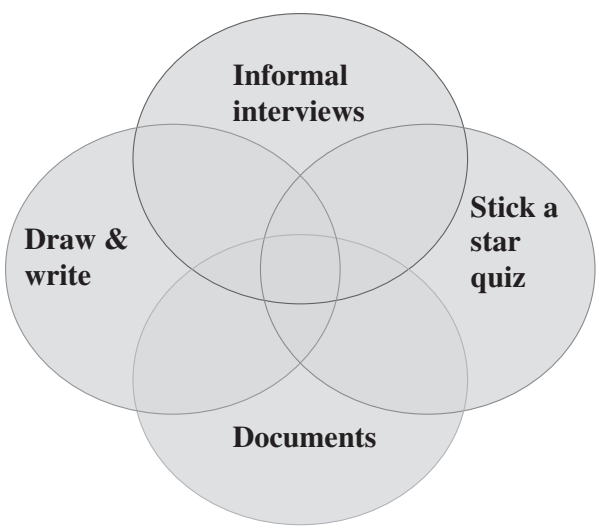

Figure 1 Field work: modes of data collection.

more stars. The idea for this activity stemmed from a pots and beans activity described and used by O'Kane (2000). Finally, admission assessment forms, information sheets, ward/hospital policies and philosophies were collated.

Field notes, which comprised of description of observations, observer comments, sketches of the environment, paraphrased documentation of informal interviews (which also included children's description of their drawings and responses to questions on the 'stick a star' quiz), reflective notes and thoughts about emerging issues, were typed into a computer package after each ward visit. Reflexive notes were also recorded particularly in relation to the researcher's role, involvement and influence throughout the data collection/ analysis process and any thoughts that arose in relation to methods, ethics or general challenges. One main concern often raised in relation to observational research is the effect of the observer on the observed. Through his or her very presence, the observer can disturb the natural environment and trigger a change in typical human behaviour. It is possible that at times health professionals could have altered their behaviour in the presence of the researcher (first author). However, it is believed that the ad hoc coming and going of the researcher, the busy noisy real life environment and the prolonged time spent on the children's ward in some way combated any sustainability in behaviour changes. As Fetterman (1998, p. 36) contends 'given time, people forget their 'company' behavior and fall back into familiar patterns of behavior'.

\section{Ethical considerations}

Ethical approval to conduct the study was granted by the University Ethics Committee and Scientific and Ethics Committees of the hospital study site. Access to the hospital was negotiated with the Chief Executive Officer, Director of Nursing and Medical Board. Health professionals were informed about the nature and intent of the study through verbal information sessions, written information packs and posters displayed in various departments. Written consent was obtained from both parents and children. Separate information sheets and consent forms were prepared for parents and children. Two children from our multi-disciplinary research advisory group assisted with reviewing drafts of the child-specific information sheet and consent forms, which were modified to incorporate their feedback. Ongoing renegotiated verbal consent was also frequently obtained, from children, at various times of the informal conversations and participant observations. It was made explicitly clear to children that participation was voluntary and they had the right to refuse and withdraw at any time without penalty. Confidentiality was upheld and children's identity protected by assigning pseudonyms.
Figure 2 Sample stick-a-star quiz (completed by Rosie 11 years).

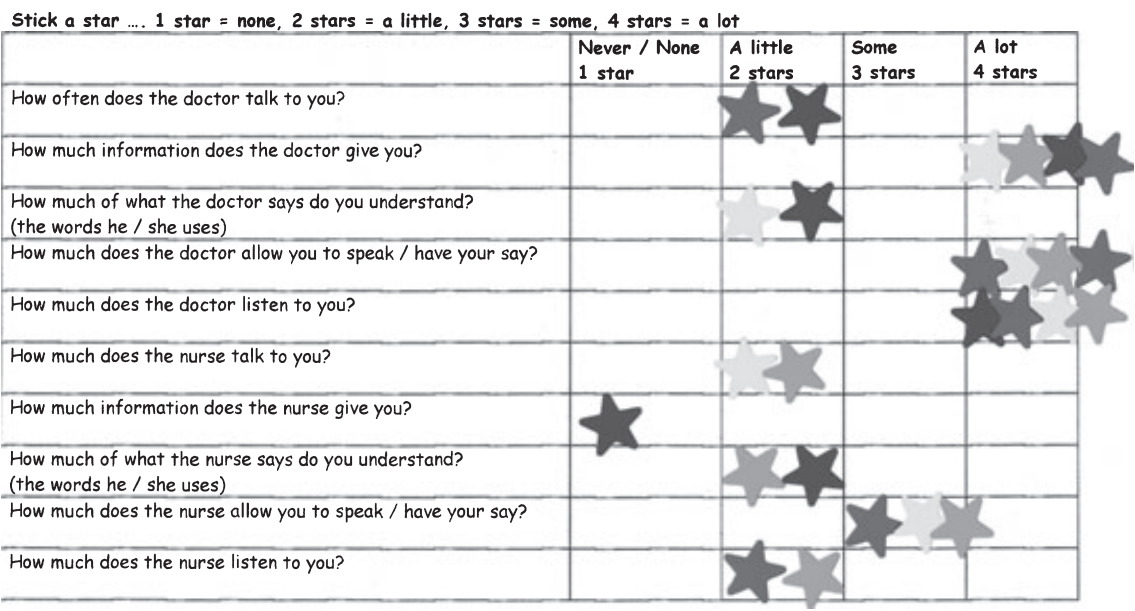




\section{Data analysis}

Through the daily process of recording field notes data analysis began. Daily reflections often informed the next day's data collection with new issues to explore, verify or refute emerging themes. After complete withdrawal from the field, an intense and lengthy period of data analysis took place. All field notes were collated and printed copies complied. Coffey and Atkinson (1996) provided structure and direction for deconstructing and reconstructing data through the processes of open coding and categorisation. The process began by reading and rereading the data in its entirety to obtain a holistic picture of 'what's going on here?' Following this handwritten marginal notes were recorded on paper copies in an attempt to decipher 'what is it saying?' Using several Microsoft Word documents, the data were decontextualised through the process of coding, cutting and pasting pieces for each similar code into a separate document.

Initially field notes from conversations were coded in an attempt to stay close to the voice of the child. Observational field notes were then separately coded. Next, a file was created for each child case containing individual conversations and observations pertinent to that child, which were jointly examined to identify comparable and contradictory issues. Following this all codes and categories were amalgamated; converging both emic and etic perspectives. The data were also examined across two different age brackets, $6-11$ and $12-$ 16 years, in an attempt to identify any stark differences between younger and older children. To assist with data management, such as code classification and data retrieval, the software package NUD"IST was employed. However, to expand upon and transform these categories further, and recontextualise the data, manual analysis was returned to. This involved a period of recurrently working with the data, recording memos, asking questions, building and collapsing and reforming categories to move beyond mere coding and categorising to interpretation. Credibility was enhanced by repeatedly referring back to original field notes and inferences verified through ongoing discussions among the three authors.

\section{Results}

The nature of communication for children admitted to a children's ward in a specialist children's hospital may be understood through the core conceptual image of 'visibleness'. 'Visible-ness' goes beyond merely representing 'vision'; it also encompasses 'voice'. This could be understood in the context of the famous proverb 'children should be seen but not heard'. This well-known adage incorporates two elements 'to be seen' and 'heard'. It is these two facets 'vision' and 'voice' that constitute the core concept of 'visible-ness'. 'Visible-ness' explicates the degree to which children were, or wanted to be, included in the communication process and the extent to which children's agenda was addressed. This core concept of 'visible-ness' was seen to exist along a continuum consisting of two distinct polar positions, conceptually labelled 'being overshadowed' and 'being at the forefront' and illustrated in Fig. 3. In an attempt to explicitly display the elements of the conceptual poles, 'being overshadowed' and 'being at the forefront', two scenarios are presented later. These scenarios were enacted from an amalgamation of data taken from the first author's ethnographic field notes.

\section{'Being overshadowed'}

The polar position 'being overshadowed' conceptualises the position where children were least visible within the communication process. In this position children were marginal to the communication process, standing in the background overshadowed by their parents and health professionals. In this first scenario, we meet Jane who occupies the overshadowed end of the continuum:

\section{Scenario 1}

Jane ( 8 years) was admitted with a really bad pain in her side. The doctors had seen her in the emergency department but she couldn't really remember what they had said, they had mostly talked to her mother, but she didn't care because she was too sore and just wanted the pain to go away. Now, the doctor had come to see Jane on the children's ward and she wished he would talk to her and not just her mother. He did acknowledge Jane by asking her how she was. However, despite not feeling great, Jane politely stated she was fine. The doctor focused his attention on examining Jane's tummy, pressing in and out and asking is it sore here, and here? Jane heard the doctor tell her mother that she needed to have an operation to remove her appendix. Jane wished they'd talk to and inform her about what was going on. She wondered about having to have an operation. She was scared and nervous about what they were going to

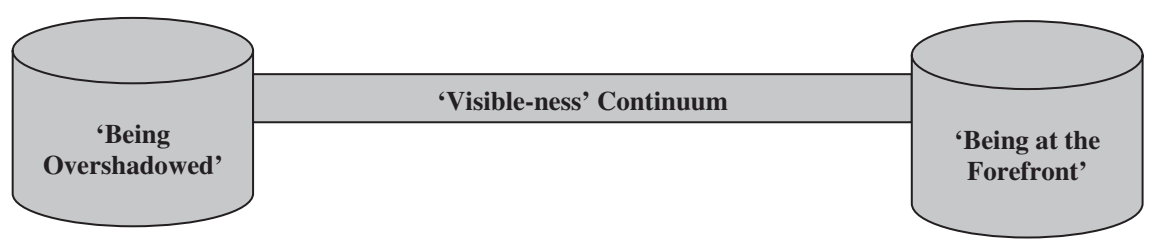

Figure 3 Core concept: 'visible-ness' continuum. 
do, would it hurt? A while later that afternoon, the anaesthetist came and although he did talk directly to Jane it was mainly to ask her a series of closed questions. At times when the anaesthetist was asking her questions her mother interjected not only to answer for her but also to ask the anaesthetist questions. Before he left he said to Jane 'don't worry...you'll be asleep'. Jane wanted to ask more about her operation but the doctors always seemed busy.

The above scenario serves to illustrate Jane occupying a background position within the communication process. Jane stood in the background of the communication process because the flow of the conversation was predominantly directed towards her mother. Jane was not communicated with directly by the doctor, but rather the doctor and her mother conversed about her in her presence. The doctor relayed information to Jane's mother and not directly to Jane. Jane listened in the background and overheard that she needed to have an operation. Consequently, Jane wondered and worried about what was going to happen. Later, when the anaesthetist arrived Jane remained in the background again with communication directed mostly to her mother.

Arguably, the anaesthetist did communicate directly with Jane by directing a series of closed questions to her. However, this was largely focused on the anaesthetist's and not Jane's agenda. Indeed on occasions when the anaesthetist did attempt to communicate with Jane, Jane's mother interrupted and blocked the interaction. In an attempt to dispel any concerns, Jane might have had the anaesthetist prematurely reassured her by stating 'don't worry...you'll be asleep'. This not only blocked Jane's expression of her concerns but also it dismissed any worries she may have had. As in Jane's case, the consequence of this marginal position for children was that it restricted their involvement in the communication process. Their voice was not heard, nor was their agenda addressed.

\section{'Being at the forefront'}

The pole 'being at the forefront' conceptualises the position where children were most visible within the communication process. Children were the focal point of the communication process, holding a leading position, with the health professional communicating directly with them, or simultaneous with them and their parents. In this second scenario, we meet Roger who occupies the frontal end of the continuum:

\section{Scenario 2}

Roger (10 years) was admitted after a serious football tackle which resulted in him breaking his leg. Although he was in severe pain when he arrived at the emergency department he remembers the doctors and nurses attending to him and orientating him to what they were doing. They spoke directly to him asking him about what had happened? While Roger was relaying his story the doctor looked directly at him, stopped what he was doing and joked with him about his football skills. The doctor explained that he thought one of his leg bones might be fractured, which he explained just meant broken, but to confirm this he needed to get an x-ray of his leg. Following his $\mathrm{x}$-ray (Roger's mother had now arrived) the doctor relayed the result to, and showed Roger on his x-ray, that one of the bones in his leg was broken. The doctor went on to explain to Roger that he would need an operation to fix the break. The doctor asked Roger how he felt about having an operation. Roger stated he didn't know because he had never had one before. The doctor informed him about what it would be like and what they were going to do. He also told him that after the operation his leg would be in a plaster cast, he wouldn't be able to walk and would need to learn how to use crutches. Then, the doctor provided Roger with an opportunity to ask questions. Roger asked, when would he have his operation, how long would it take and when could he go home?

In contrast to scenario 1 , this second scenario above serves to illustrate Roger occupying a frontal position within the communication process. Roger occupied a frontal position within the communication process because he was communicated directly with by the doctor. The doctor openly sought Roger's view about what had happened and allowed him to tell his story. The doctor actively listened to what Roger was saying. He incorporated some humour and social chat about Roger's football skills. Despite the presence of Roger's mother, comprehensible information was relayed to Roger about what was wrong with him and the proposed plan of action. The doctor explored how Roger felt about having an operation and provided him with detailed information about what was going to happen both in theatre and postoperatively. Roger was also afforded with an opportunity to raise issues of concern to him by being allocated an opportunity to ask questions. This allowed Roger to address his own agenda. Like Roger, the implication of this frontal position for children was that they felt valued and respected through their inclusion in the communication process. But not only this, the consequence of being included was that it facilitated being open to the child's agenda.

\section{Discussion}

As illustrated through the earlier two scenarios, the nature of communication for children admitted to the children's ward was conceptualised as existing along a 'visible-ness' continuum. Essentially there were two core dimensions, 'being overshadowed' and 'being at the forefront'. The 'overshadowed' 
end of the 'visible-ness' continuum represented times when children occupied a background (least visible) position within the communication process (as illustrated in scenario 1). This finding concurs with previous studies which reported that medical consultations were mostly dyadic exchanges between parents and health professionals with children largely marginalised (Tates et al. 2002, Young et al. 2003, Coyne et al. 2006). Furthermore, this finding also lends support to other recent studies exploring children's views of hospital/ health care, which suggested that children expressed a strong desire for health professionals to direct clear, honest, accurate and more in-depth information to them (Horstman \& Bradding 2002, Boylan 2004, Salter \& Stallard 2004, Smith \& Callery 2005). Contrastingly, the 'forefront' end of the 'visible-ness' continuum represented times when children occupied a frontal (most visible) position within the communication process (as illustrated in scenario 2). This frontal pole of the 'visible-ness' continuum also coincides with prior studies, investigating the child's contribution in doctorparent-child consults, which reported an increase in child involvement over the years in all parts of the consult, especially the physical examination (Meeuwesen \& Kaptein 1996, Tates et al. 2002). The child's increased involvement was partly as a result of the doctor allocating the child more space within the consultation and also partly because of the child taking more initiative. This equates with findings from this study (Lambert et al. 2007b).

Notwithstanding this, however, an inherent difficulty in presenting the findings along a continuum with two distinct conceptual poles is the risk that either end of the continuum would be considered 'ideal'. The outstanding question is what is the 'ideal' point for the child to occupy on the 'visibleness' continuum? Is it the overshadowed or the frontal end of the 'visible-ness' continuum? There is the danger that the frontal position would be regarded as the 'ideal' stance to hold. However, as emerged in this study (Lambert et al. $2007 \mathrm{~b}$ ), not all children necessarily wanted to occupy the frontal position at all points in times. At some particular times and for some particular situations, children were happy to remain in the background as passive bystanders, overshadowed by their parents. For example, illustrated briefly at the beginning of scenario 1, when Jane was overshadowed initially she did not care because she just wanted to get rid of her pain, but later on, when she was overshadowed again, at a different time, she wanted to be at the forefront. This coincides with previous work which reported that not all children want to know everything (Boylan 2004); some children find information overwhelming (Gibson et al. 2005) and some children are content when communication is directed to their parent because they fear hearing bad things
(Coyne et al. 2006). Notwithstanding this, Coyne et al. (2006) presented their framework of consultation as a hierarchy of seven levels of participation. This hierarchical framework failed to present the voice of a minority of children in their study, that is, the children who do not particularly want to be involved or consulted with for whatever reason, nor did they identify what situates children at one level or another or how children move 'up and down' the levels. Gale et al. (2004) urge caution on the reorientation towards partnership, especially as it is driven primarily from a hierarchical 'top down' as opposed to a patient 'bottom up' approach. This has implications for children who perhaps, for whatever reason, are not ready to embrace such responsibility.

In light of previous research (Beresford \& Sloper 2003, Coyne et al. 2006, Kilkelly \& Donnelly 2006), one might surmise that children of an older age and those who were regular attendees to the children's ward would be more likely to occupy the frontal position of the 'visible-ness' continuum. However, findings from this study do not conclusively support this suggestion (Lambert et al. 2007a, b). In this study there were instances when younger children (aged 611 years) and children with no previous hospital experience occupied the forefront of the 'visible-ness' continuum, thus were actively involved in the communication process (Lambert et al. 2007b). There were also instances when older children (aged 12-16 years) and regular attendees were marginalised in the communication process, thus occupied the overshadowed end of the 'visible-ness' continuum (Lambert et al. 2007a). Differing beliefs surrounding specific age competencies were also highlighted by Young et al. (2003), who confirmed that age was not particularly useful in explaining children's preferences for information. Furthermore, being of an older age and a regular attendee did not mean that these children always wanted to occupy the frontal position of the 'visible-ness' continuum. These findings highlight the difficulty with explicitly applying age or prior experience as criteria for which to determine the child's level of involvement in the communication process. This statement is supported by Ellis and Leventhal (1993) who affirmed that the increased trend to enhance children's decision-making responsibility was contrary to children's preferences. One difficulty in interpreting previous research findings, which state that children of an older age tend to be involved more and are perhaps more self-initiated within the communication process, is the variance of age. Frequently the terms younger and older are used without explicitly stating what age is categorised as younger or older. Indeed, in Coyne et al.'s (2006) study children themselves identified an age range from 9 to 18 years as to when they should be actively 
involved in decision making, with some children stating that age did not matter; rather it should be determined on an individualised basis. This was also highlighted by children in Ellis and Leventhal's (1993) study, whereby the level of responsibility children wanted to undertake differed depending on the type of decisions to be made.

Therefore, we urge caution in judging one end of the continuum as superior to the other. Debatably, 'being at the forefront' represents more effective principles of the communication process; however, this does not necessarily mean that children, of whatever age or condition, want to solely occupy the frontal position of the communication process. As evident in this study (Lambert et al. 2007a, b), children did not exclusively occupy a frontal or background position in the communication process; they were in constant motion, back and forth, along the continuum between the two extreme poles of 'being overshadowed' and 'being at the forefront'. What is important to consider is, what are the various factors that place the child at either end of the continuum? Although it is beyond the scope of this article to explicitly discuss the various factors which accounted for children occupying and moving between one end ('being overshadowed') or the other ('being at the forefront'), the findings established that children's visibility in the communication process was contingent on four key factors (refer to Table 2): (1) children themselves, in terms of their ability to articulate or their desire to engage in the communication process; (2) health professionals and (3) parents recognition of children as part of the communication process or perceived need to be engaged in the process and (4) the hospital environment itself (Lambert \& Glacken 2006).

All of these factors both singularly or in combination had the capacity to enhance or silence the child's voice. A fundamental question to consider is how can these factors be flexibly manoeuvred to meet the individual needs of children depending on where the child wants to be along the continuum at any particular point in time? To do this, there is the requirement to place more emphasis on developing strategies for assessing and re-assessing children's communication needs, illuminated in this study through the deficient documentary evidence of the assessment of children's communication needs (Lambert \& Glacken 2006).

\section{Relevance to clinical practice}

For practice, this study highlights the need for all health professionals to embrace the individualism of each child patient with regard to their specific communication needs.

\section{Strengths and limitations}

We acknowledge that because the findings were drawn from one children's ward in one specialist children's hospital they cannot be declared as representative of all children's wards/

Table 2 Influential 'movers': pushing and pulling children back and forth along the 'visible-ness' continuum

\begin{tabular}{|c|c|c|c|}
\hline Health professional & Child & Parent & Environmental \\
\hline $\begin{array}{l}\text { Directional flow of the interaction } \\
\text { To child or parent } \\
\text { Communication skills } \\
\text { Closed/open questioning style } \\
\text { Effective/ineffective listening } \\
\text { Offering premature reassurance } \\
\text { Inviting child to ask questions } \\
\text { Information provision } \\
\text { Amount } \\
\text { Comprehension } \\
\text { Developmental appropriateness } \\
\text { Status of health professional } \\
\text { Doctor 'knowledgeable expert' } \\
\text { Nurse as intermediary; } \\
\text { transmitting and translating } \\
\text { information } \\
\text { Humanistic Qualities } \\
\text { Nice, friendly, humorous, } \\
\text { approachable } \\
\text { Presence }\end{array}$ & $\begin{array}{l}\text { Child self-initiation } \\
\text { Child-initiating interactions } \\
\text { Child butting in } \\
\text { Child asking health professional } \\
\text { questions } \\
\text { Child asking parent questions } \\
\text { Interacting with other children } \\
\text { Observing what is happening } \\
\text { on ward } \\
\text { Age/maturity } \\
\text { Younger or older } \\
\text { Previous experience/condition } \\
\text { Acute or chronic } \\
\text { Regular attendee or not } \\
\text { School } \\
\text { Primary/secondary }\end{array}$ & $\begin{array}{l}\text { Parental presence } \\
\text { Parent 'butting in' } \\
\text { Parent as intermediary; } \\
\text { transmitting and } \\
\text { translating information }\end{array}$ & $\begin{array}{l}\text { Internal: ward context } \\
\text { Busy task-oriented health } \\
\text { professionals } \\
\text { Busy preoccupied children } \\
\text { External: children in society } \\
\text { Construction and re-construction } \\
\text { of children in society } \\
\text { Influential documents, for } \\
\text { example United Nations } \\
\text { Convention Rights of Children, } \\
\text { National Children's Strategy, } \\
\text { Health Strategies/Frameworks }\end{array}$ \\
\hline
\end{tabular}


hospital settings. However, valuable insights are provided for other health professionals to reflect upon, appraise and challenge their experiences and practices. Health professionals' acquaintance/familiarity with the findings would determine the applicability to other settings. Feedback from presenting at various international venues affirmed resonance with many aspects of these findings, enhancing the credibility of the results. In contrast to narrow breadth, the inherent value in employing an ethnographic approach was the depth of data gathered through the integration of both observations and interviews; 'being there' over an extended period of time, 'seeing and hearing' what was happening, 'listening to' what participants had to say and gaining insight into the broader context where the process of communication occurred. Furthermore, we believe that the prolonged time spent in the naturalistic context of the children's ward, to capture both 'emic' and 'etic' perspectives, and the use of non-rigid multi-modes of data collection, augmented the trustworthiness of the study and assisted in some way to address concerns often raised in the literature about the accuracy, suggestibility, consistency and truthfulness of children's responses (Docherty \& Sandelowski 1999). While this study did not seek the views of other stakeholders, such as parents and health professionals, which would have added further valuable dimensions to the findings, the aim was to focus solely on and represent the views of children. Further research to collectively explore the views of all actors within the communication process is warranted.

\section{Conclusion}

The 'visible-ness' continuum attempts to illustrate the varying experiences of the child participants. There were instances of positive encounters with health professionals and also instances of less positive encounters and ineffective patterns of communication. There were times when children occupied the background and there were other times when these same children occupied the forefront of the communication process. Children did not exclusively occupy either a frontal or background position in the communication process; rather they were in constant motion, back and forth, along the continuum between the two extreme poles of 'being overshadowed' and 'being at the forefront'. Numerous factors accounted for this constant interchange between the forefront and background, namely child, parent, health professional and environmental factors. A key recommendation from this study is that there is a need for communication assessment strategies to determine the 'ideal' position the child would like to occupy, at any given point in time, along the 'visibleness' continuum.

\section{Acknowledgements}

This study was funded in part by the Office of the Minister for Children; National Children's Strategy Research Scholarships. Further financial support was also provided by the Child Health Foundation and Director of Nursing of the Children's Hospital, who for anonymity reasons cannot be named. The authors would like to pay tribute to the health professionals, parents and especially the children who shared their valuable story and allowed the first author entry to their world.

\section{Contributions}

Study design: VL, MG, MMcC; data collection and analysis: VL and manuscript preparation: VL, MG, MMcC.

\section{References}

Agar M (1986) Speaking of Ethnography. Qualitative Research Methods. Series 2. Sage Publications, London.

Ahmann E \& Johnson BH (2000) Family-centred care: facing the new millennium. Pediatric Nursing 26, 87-90.

Alsop-Shields L (2002) The parent-staff interaction model of pediatric care. Journal of Pediatric Nursing 17, 442-449.

Arnold E (2003) Theoretical perspectives and contemporary issues. In Interpersonal Relationships: Professional Communication Skills for Nurses (Arnold E \& Underman Boggs K eds). W.B. Saunders, Philadelphia, pp. 1-27.

Beresford BA \& Sloper P (2003) Chronically ill adolescents' experiences of communicating with doctors: a qualitative study. Journal of Adolescent Health 33, 172-179.

Boylan P(2004) Children's Voices Project: Feedback from Children and Young People About Their Experience and Expectations of Healthcare. Commission for Health Improvement. Available at: http://www.chi.gov.uk/_db/_documents/04012717.pdf (accessed 12 August 2007).

Bradding A \& Horstman M (1999) Using the write and draw technique with children. European Journal of Oncology Nursing 3, 170-175.

Bricher G (1999) Paediatric nurses, children and the development of trust. Journal of Clinical Nursing 8, 451-458.

Bronfenbrenner U(1979) The Ecology of Human Development. Experiments by Nature and Design. Harvard University Press, London.

Brown J \& Ritchie JA (1989) Nurses' perceptions of their relationships with parents. Maternal Child Nursing Journal 18, 79-96.

Carney T, Murphy S, McClure J, Bishop E, Kerr C, Parker J, Scott F, Shields C \& Wilson L (2003) Children's views of hospitalisation: an exploratory study of data collection. Journal of Child Health Care 7, 27-40.

Coffey A \& Atkinson P (1996) Making Sense of Qualitative Data. Sage Publications, London.

Coyne I, Hayes E, Gallagher P \& Regan G (2006) Giving Children a Voice: Investigation of Children's Experiences of Participation in 
Consultation and Decision-Making in Irish Hospitals. Office of the Minister for Children, Dublin. Available at: http://www.omc.gov.ie/documents/research/Giving_Children_a_Voice.pdf (accessed 12 August 2007).

Department of Health (2003) Getting the Right Start: National Service Framework for Children, Young People and Maternity Services - Standard for Hospital Services. Department of Health, London. Available at: http://www.dh.gov.uk/en/Publicationsand statistics/Publications/PublicationsPolicyAndGuidance/DH_4008273 (accessed 12 August 2007).

Department of Health \& Children (2000) The National Children's Strategy. Our Children - Their Lives. Stationery Office, Dublin. Available at: http://www.dohc.ie/publications/national_childrens_ strategy.html (accessed 12 August 2007).

Docherty S \& Sandelowski M (1999) Focus on qualitative methods: interviewing children. Research in Nursing \& Health 22, 177185.

Ellis R \& Leventhal B (1993) Information needs and decision-making preferences of children with cancer. Psycho-Oncology 2, 277-284.

Emond R (2005) Ethnographic research methods with children and young people. In Researching Children's Experience. Approaches and Methods (Greene S \& Hogan D eds). Sage Publications, London, pp. 123-139.

Espezel HJE \& Canam CJ (2003) Parent-nurse interactions: care of hospitalised children. Journal of Advanced Nursing 44, 34-41.

Fetterman DM (1998) Ethnography, 2nd edn. Sage Publications, London.

Gale J, Olumide G \& Bury M (2004) 'It takes three to tango': a framework for understanding patient partnership in paediatric clinics. Social Science \& Medicine 59, 1071-1079.

Gibson F, Richardson A, Hey S, Horstman M \& O’Leary C (2005) Listening to Children and Young People with Cancer. Centre for Nursing and Allied Health Professionals Research, Institute of Child Health, Great Ormond Street Hospital, London. Available at: http://www.kcl.ac.uk/teares/nmvc/external/docs/listening-tochildren-final-reportjuly_2005.pdf (accessed 12 August 2007).

Hallstrom I \& Elander G (2004) Decision-making during hospitalisation: parents' and children's involvement. Journal of Clinical Nursing 13, 367-375.

Hallstrom I, Runeson I \& Elander G (2002) Observed parental needs during child's hospitalisation. Journal of Pediatric Nursing 17, 140-148.

Hammersley M \& Atkinson P (1995) Ethnography: Principles in Practice, 2nd edn. Routledge, London.

Hammersley M \& Atkinson P (2007) Ethnography: Principles in Practice, 3rd edn. Routledge, London.

Hill M, Laybourn A \& Borland M (1996) Engaging with primaryaged children about their emotions and well-being: methodological considerations. Children \& Society 10, 129-144.

Hooker L (1997) Information needs of teenagers with cancer: developing a tool to explore the perceptions of patients and professionals. Journal of Cancer Nursing 1, 160-168.

Horstman M \& Bradding A (2002) Helping children speak up in the health service. European Journal of Oncology Nursing 6, 75-84.

Ireland L \& Holloway I (1996) Qualitative health research with children. Children \& Society 10, 155-164.

Johnson M (1995) Coping with data in an ethnographic study. Nurse Researcher 3, 22-33.
Kelsey J \& Abelson-Mitchell N (2007) Adolescent communication: perceptions and beliefs. Journal of Children's and Young People's Nursing 1, 42-49.

Kilkelly U \& Donnelly M (2006) The Child's Right to be Heard in the Healthcare Setting: Perspectives of Children, Parents and Health Professionals. Office of the Minister for Children, Dublin. Available at: http://www.omc.gov.ie/documents/research/The_Childs_ Right_to_be_Heard_in_the_Healthcare_Setting.pdf (accessed 12 August 2007).

Lam LW, Chang AM \& Morrissey J (2006) Parents' experiences of participation in the care of hospitalised children: a qualitative study. International Journal of Nursing Studies 43, 35-45.

Lambert V \& Glacken M (2006) Children's Visibility: The Nature of Communication for Children Admitted for Acute Care in a Specialist Paediatric Hospital in the Republic of Ireland. Paper presented at the 17th International Nursing Research Congress. 'Advancing Knowledge and Community Globally Through Collaboration', Montreal, Canada.

Lambert V, Glacken M \& McCarron M (2007a) 'Being Overshadowed': One Aspect of the Process of Communication Between Children and Health Care Professionals in a Paediatric Hospital Setting. Paper presented at the RCN International Nursing Research Conference, Dundee, UK.

Lambert V, Glacken M \& McCarron M (2007b) 'Being at or Brought to the Forefront' - One Dimension of the Nature of Communication for Children Admitted to a Specialist Paediatric Hospital in the Republic of Ireland. Paper presented at the 3rd International Congress on Pediatric Nursing. 'Children and Young People's Nursing: Looking Forward', Athens, Greece.

MacKenzie AE (1994) Evaluating ethnography: considerations for analysis. Journal of Advanced Nursing 19, 774-781.

Meeuwesen L \& Kapten M (1996) Changing interactions in doctorparent-child communication. Psychology and Health 11, 787-795.

O'Kane C (2000) The development of participatory techniques. Facilitating children's views about decisions which affect them. In Research with Children. Perspectives and Practices (Christensen $\mathrm{P}$ \& James A eds). Routledge Falmer, London, pp. 136-160.

Paliadelis P, Cruickshank M, Wainohu D, Winskill R \& Stevens H (2005) Implementing family-centred care: an exploration of the beliefs and practices of paediatric nurses. Australian Journal of Advanced Nursing 23, 31-36.

Pridmore P \& Bendelow G (1995) Images of health: exploring beliefs of children using the 'draw-and-write' technique. Health Education Journal 54, 473-488.

Runeson I (2002) Children's Participation in Decision-Making in Health Care. Doctoral Dissertation, Lund University, Sweden.

Salter E \& Stallard P (2004) Young people's experience of emergency medical services as road traffic accident victims: a pilot qualitative study. Journal of Child Health Care 8, 301-311.

Shields L, Kristensson-Hallstrom I \& O'Callaghan M (2003) An examination of the needs of parents of hospitalized children: comparing parents' and staff's perceptions. Scandinavian Journal of Caring Sciences 17, 176-184.

Shields L, Hunter J \& Hall J (2004) Parents' and staff's perceptions of parental needs during a child's admission to hospital: an English perspective. Journal of Child Health Care 8, 9-33.

Shin H \& White-Traut R (2005) Nurse-child interaction in an inpatient paediatric unit. Journal of Advanced Nursing 52, 56-62. 
Silverman D (1987) Communication and Medical Practice: Social Relations in the Clinic. Sage Publications, London.

Smith L \& Callery P (2005) Children's accounts of their preoperative information needs. Journal of Clinical Nursing 14, 230-238.

Smith L, Coleman V \& Bradshaw M (2002) Family Centred Care. Palgrave, Basingstoke.

Soderback M \& Christensson K (2007) Care of hospitalized children in Mozambique: nurses' beliefs and practice regarding family involvement. Journal of Child Health Care 11, 53-69.

Strong P (1979) The Ceremonial Order of the Clinic. Routledge \& Kegan Paul, London.
Tates K, Meeuwesen L, Elbers E \& Bensing J (2002) 'I've come for his throat': roles and identities in doctor-parent-child communication. Child Care Health and Development 28, 109-116.

VanDulmen AM (1998) Children's contributions to pediatric outpatient encounters. Pediatrics 102, 563-568.

Ygge BM, Lindholm C \& Arnetz J (2006) Hospital staff perceptions of parental involvement in paediatric hospital care. Journal of Advanced Nursing 53, 534-542.

Young B, Dixon-Woods M, Windridge KC \& Heney D (2003) Managing communication with young people who have a potentially life threatening chronic illness: qualitative study of patients and parents. British Medical Journal 326, 305-308. 
This document is a scanned copy of a printed document. No warranty is given about the accuracy of the copy. Users should refer to the original published version of the material. 
This document is a scanned copy of a printed document. No warranty is given about the accuracy of the copy. Users should refer to the original published version of the material. 